Case Reports

\title{
Demonstration of the Structural Resiliency of Damaged Sentryglas Laminated Heat Strengthened Glass Fins in Full Scale Testing
}

\author{
${ }^{1}$ Fred Veer, ${ }^{2}$ Diana de Krom and ${ }^{3}$ Rob Nijsse \\ ${ }^{1}$ Faculty of Architecture, Delft University of Technology, The Netherlands \\ ${ }^{2} A B T$, The Netherlands \\ ${ }^{3}$ Faculty of Civil Engineering, Delft University of Technology, The Netherlands
}

\section{Article history}

Received: 17-11-2020

Revised: 06-02-2021

Accepted: 11-02-2021

Corresponding Author:

Fred Veer

Faculty of Architecture, Delft University of Technology, The Netherlands

Email: f.a.veer@tudelft.nl

\begin{abstract}
A unique structural design was made for the glass façade of the Co-Creation Center building in Delft. The roof is completely carried by the glass fins. The fins are laterally stabilized by being included in the triple glazed façade. To certify the safety of the design full scale tests on the fins were done at Delft University of Technology. Due to a transportation accident the fins were damaged at one end. This allowed an additional study into the effect of this pre-test damage on the residual compressive stressed induced by the tempering. It was found that the residual stresses were not significantly affected by the damage. During the compression tests no cracks developed at the damaged ends. A load of $200 \mathrm{kN}$, more than double the maximum design load did not produce failure in the prototypes. After intentionally seriously damaging all plies of the fins, the fins could still carry the $200 \mathrm{kN}$ load for $30 \mathrm{~min}$ without buckling or other failures being noted. Measurement of the residual stress in the outer plies of the fins after damage showed that sufficient residual stress was present in the larger fragments of the prototype to provide enough stability in combination with the Sentryglass laminating foil.
\end{abstract}

Keywords: Structural Glass, Resiliency of Structural Glass, Full Scale Testing

\section{Introduction}

Structural glass facades have developed considerably the last decades. In the development of these facades increasing transparency by using more glass and less metal is critical. Part of this development is the use of slender glass fins to provide out of plane stabilization. As these long slender elements are buckling sensitive this requires significant care and attention in the design phase (Silvestru and Englhardt, 2012) give a good description of these problems. The structural safety and especially the structural redundancy is of particular concern and usually requires experimental validation of new concepts. A good analysis of this is given by (van de Rotten et al., 2020), discussing the validation of a recent design. Buckling is the main problem. Buckling of laminated glass is a complex issue. A very good overview of the problems is given by (Momeni and Bedon, 2020).

Extending the structural glass concept by integrating the fins and facade into a single structural whole, that both stabilizes the building and carries the roof is a logical next step. Two small buildings of this type have been build. The Istanbul Apple store (structural design James O'Callaghan), (USGNN, 2015) and the temple de'amour at Avillon (Nijsse, 2003; Postel and Jodidio, 2008), are good examples.

A much larger and more daring glass building using the same concept, the Co-Creation Center, has been realized in 2020 on the green village site in Delft, https://www.thegreenvillage.org/. Although intended as an all glass structure, budget limitations reduced this to an all glass façade with a non-glass roof. The development of the design is described by (de Krom et al., 2000). The Co-Creation Center (CCC) is however significantly larger, $22.5 \mathrm{~m}$ wide and $13.5 \mathrm{~m}$ deep, with a height of 6 $\mathrm{m}$, thus more than doubling the dimensions of the previous projects cited. In this design the triple glazing is directly integrated with the fins.

The Co-Creation Center in the final phase of building is shown in Fig. 1. This picture was selected as it shows both the connections to the concrete under structure as 
well as the roof. In the finished building these details are invisible. The stability cross on the right is a temporary element to stabilize the structure during building and was removed after the silicone cured. The black element at the intersection of the glass elements is only Silicone. All vertical loads of the roof are carried by the fins to the foundation. The fins also provide out of plane stability stiffening the façade against wind. The façade glazing in turn provides lateral support for the fins. The innovative design of the connection detail is shown in Fig. 2. The triple glazing is directly integrated with the glass fins using only black Silicone. This integrates the thermal insulation, the structural stabilization and the load carrying capacity into a single glass wall structure. This integration of functions into the glass design, eliminating metal supporting elements combines transparency, good building physics properties, safe structural design and high architectural appeal into a single integrated whole.

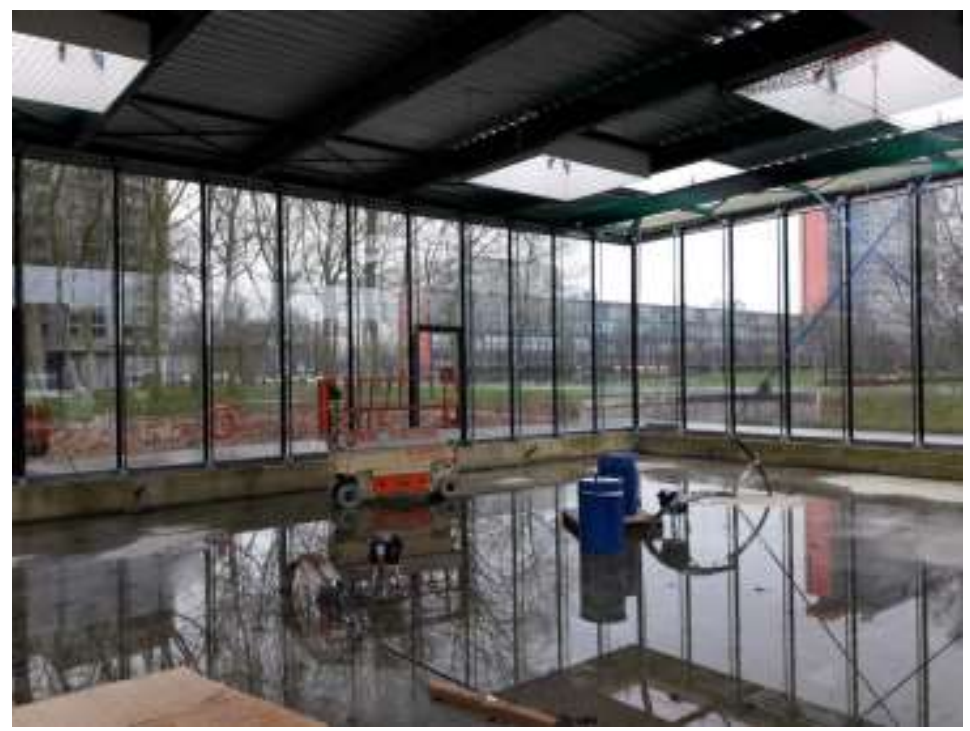

Fig. 1: Co-Creation Center in final phase of building, (de Krom et al., 2000)

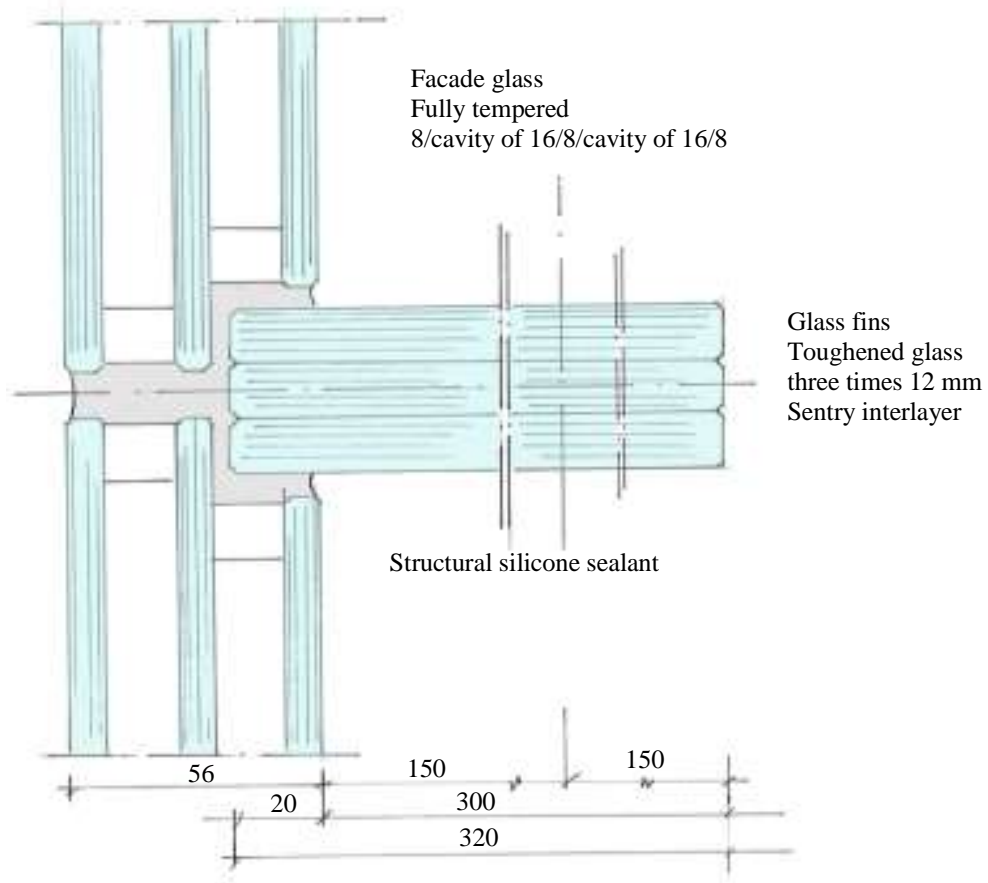

Fig. 2: Glass detail of Co-Creation Center, (de Krom et al., 2000) 
Heat strengthened Sentryglas laminated glass was selected for the fins as annealed glass was not considered strong enough and fully tempered glass was considered dangerous due to its susceptibility to impact damage and potential NiS failure, as shown by (Kasper, 2019). The green village, as an experimental site is not subject to the normal Dutch building regulations. However considering the nature of the structure and the total innovation of a new type of all glass structure, full scale compression tests of the fins were required to demonstrate the structural safety.

\section{The Glass Fins}

The glass fins are $5.5 \mathrm{~m}$ long, $320 \mathrm{~mm}$ deep and made by laminating 3 plies of $12 \mathrm{~mm}$ thick heat strengthened glass with a Sentryglass interlayer. Three specimens were made of which two were tested for this research to validate the design. One specimen was kept for later study. Glass specification was 12.12.12.44, meaning 3 plies of $12 \mathrm{~mm}$ float glass with 4 layers of Sentryglass foil each with a thickness of $0.76 \mathrm{~mm}$ between the glass plies. This was verified by measuring the thickness with digital calipers. The fins were specially made by Thieleglas for contractor $\mathrm{SiX}, \mathrm{SiX} . n l$.

The compressive surface pre-stress is critical for the strength of glass. This can be measured using optical techniques, especially looking at the changes in polarisation as laser light passes through the glass pane. This was developed by (Aben et al., 2013), into the series of Scalp scanners which can measure the (pre-) stress in float glass panes with an accuracy of $\pm 5 \mathrm{MPa}$ if the right setting are used and the device is used by a skilled operator (Glassstress.com, 2021).

Using a Scalp 5 scanner, glass stress, the compressive surface pre-stress was measured in the outer glass plies. The scalp settings used were:

- $\quad$ Fit method local

- 3rd order fitting polynomial

- Noisy background as measurements had to be taken in a hall with both artificial and natural light creating a lot of noise on the laser signal

The pre-stress was found to be $-60 \pm 8 \mathrm{MPa}$ on the center line of the specimen and $-80 \pm 10 \mathrm{MPa}$ close to the side edges. The measuring points are illustrated in Fig. 3. This spread is normal for heat strengthened glass and compares to the spread measured in smaller heat strengthened glass samples by (Veer and Rodichev, 2016).

Unfortunately the glass fins were damaged at one end when they were moved into the laboratory by staff not specifically trained to handle glass. The damage is shown in Fig. 4. The damage was measured using a contour gauge as shown in Fig. 5 to determine the depth of the damage. Essentially at the bottom corners of the specimens a triangular bite was taken out of the outer plie over a length of some $24 \mathrm{~mm}$ as shown in Fig. 5. This damage was about half of this some $40 \mathrm{~mm}$ up, over a 12 $\mathrm{mm}$ length the missing glass tapered from 12 to $6 \mathrm{~mm}$. Above $100 \mathrm{~mm}$ from the lower longitudinal edge there was no visible damage. As getting new specimens would take two months and the damaged specimens were assumed to give a conservative test result the damaged specimens were used for testing.

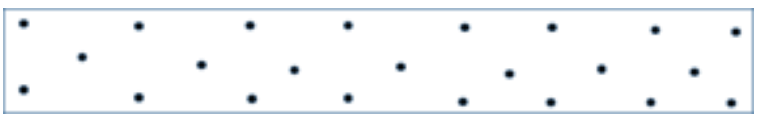

Fig. 3: Distribution of measuring points for Scalp device on glass surface

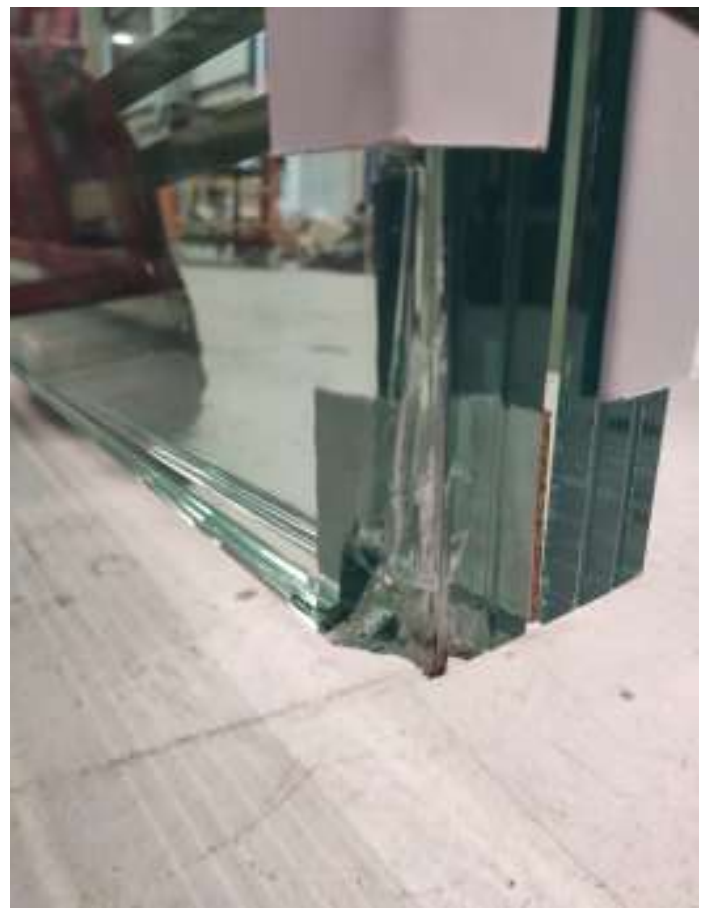

Fig. 4: Transport damage to corner of fin before testing

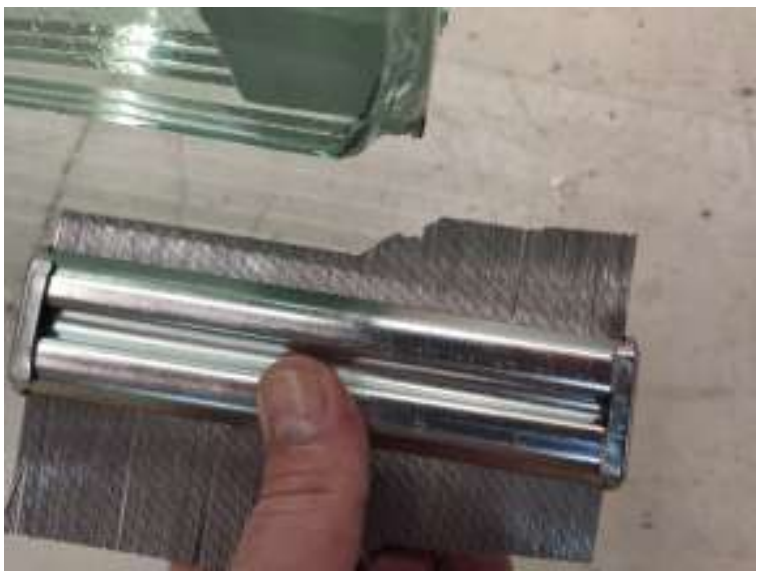

Fig. 5: Measurement of damage using a contour gauge 
Scalp measurements of the compressive surface prestress at the edge of the damage showed values of $-60 \pm 15 \mathrm{MPa}$. This is comparable to the values on the undamaged center line of the specimens. This indicates that the damage should have little effect on the glass strength in this case.

This unfortunate accident illustrates very well the damage tolerance of heat strengthened glass. Fully tempered glass elements would not have survived this type of accident.

\section{Compression Testing of the Fins}

The problem with full scale tests is that there are not many machines available that fit a $5.5 \mathrm{~m}$ column. The Stevin laboratory of the faculty of civil engineering and geo-sciences of Delft University of Technology has a 5 MN Amsler hydraulic testing machine. For these experiments it was fitted with a $500 \mathrm{kN}$ load cell. The 70 year old machine has been slightly updated in that the load can be measured digitally and the displacement of the hydraulic cylinder can be measured using a linear transducer. However loading rate control is manual.

As the fin in the CCC pavilion is laterally stabilized by the triple glazing, as shown in Fig. 2, this was simulated by stabilising the fin by siliconing it into two steel profiles which provide the lateral resistance during the test. The dimensions of the steel profiles were calculated by ABT, ABT.eu, to approximate the lateral stiffness provided by the triple glazing. The resulting specimen is shown in Fig. 6. The specimen in the safety cage is shown in Fig. 7. The fixed steel connection detail at the bottom and hinged connection detail at the top replicate exactly those designed for the CCC pavilion and are shown in Fig. 8 and 9. The displacement of the hinged bolted connection on top is limited to $25 \mathrm{~mm}$ to avoid putting vertical loads into the façade elements of the CCC pavilion. As a result the maximum load on the glass in the test was limited to $200 \mathrm{kN}$. At a higher load the steel connection elements touch and load is transferred from the glass to the steel profile.

The specimens were placed in the test setup with the damaged ends downwards to provide consistency. The design loads predicted by the structural design bureau, ABT, on the fin are given in Table 1. These design loads are:

- Building is undamaged, roof load goes evenly through all columns. This is the normal situation.

- One column is no longer load bearing and the force is redistributed through adjacent columns. This situation allows for severe damage to a single column

- The failure load of the column calculated by the Finite Element Design software based on buckling of an undamaged column
The specimen condition, applied loads and hold times used are given in Table 2. The loading rate was approximately $10 \mathrm{kN}$ a minute. Specimen 1 was loaded in steps of $25 \mathrm{kN}$ with a hold time of $3 \mathrm{~min}$ at the end of each step. A hold time was used to check if there was any time dependent deformation as the Sentryglass interlayer can show creep, although this is not usually observed at room temperature, (Louter, 2011). Specimen 2 was loaded in steps of $50 \mathrm{kN}$ with a hold time of $3 \mathrm{~min}$ to the maximum of $200 \mathrm{kN}$ where the load was held constant for $30 \mathrm{~min}$.

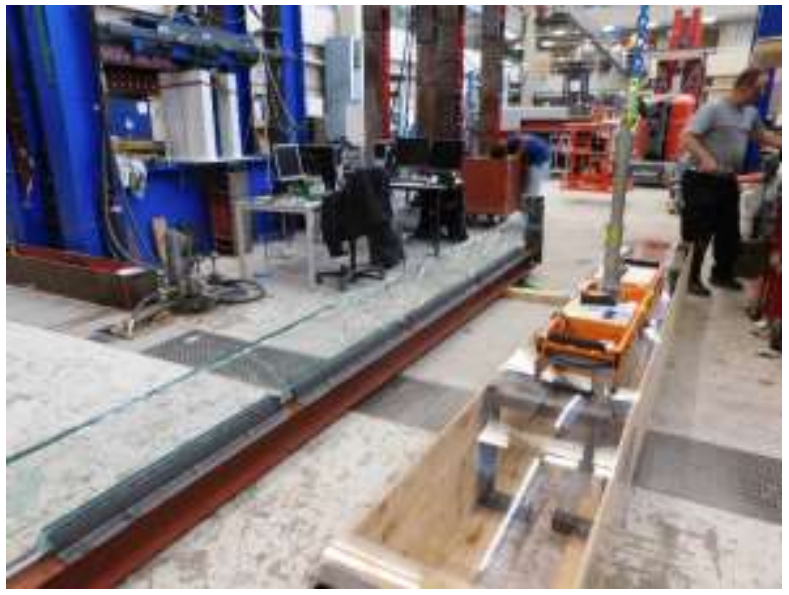

Fig. 6: Damaged specimen siliconed into steel profile which simulates the lateral support of the façade glazing in the real structure

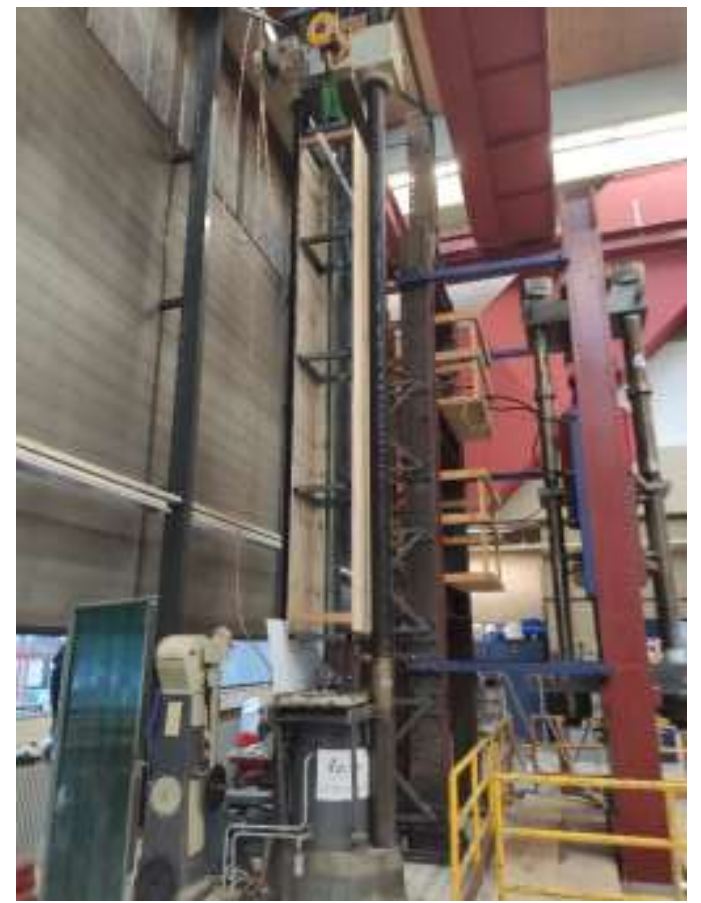

Fig. 7: Test set-up 
Fred Veer et al. / International Journal of Structural Glass and Advanced Materials Research 2021, Volume 5: 29.37 DOI: 10.3844/sgamrsp.2021.29.37

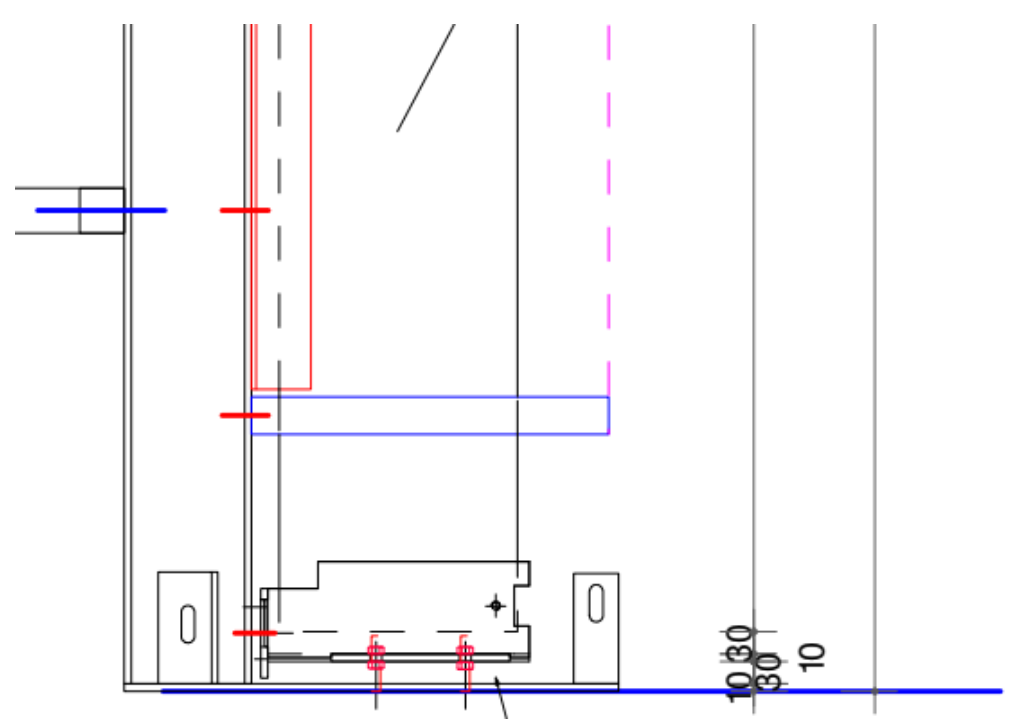

Fig. 8: Bottom connection detail of test-setup, fins are $320 \mathrm{~mm}$ wide

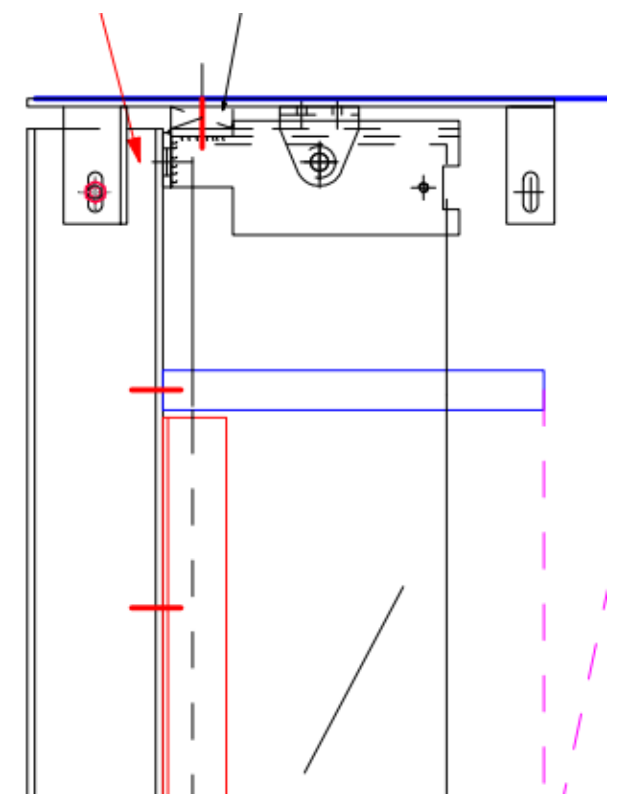

Fig. 9: Hinged top connection detail of test set-up showing hinge, fins are $320 \mathrm{~mm}$ wide

Table 1: Design loads on the fin as calculated by structural design bureau ABT, (de Krom et al., 2000)

Condition

Undamaged structure, even load distribution

Design load $(\mathrm{kN})$

Adjacent fin no longer load bearing, redistribution of load.

68.79

Predicted buckling load of laterally supported specimen

$>181$

Table 2: Summary of tests done

\begin{tabular}{llll}
\hline Test specimen & condition & Maximum load $(\mathrm{kN})$ & Hold time at maximum load $(\mathrm{s})$ \\
\hline 1 & Undamaged except for transport damage & 125 & 600 \\
1 & 1 ply damaged & 125 & 600 \\
1 & 2 outer plies damaged & 125 & 600 \\
2 & undamaged except for transport damage & 200 & 1800 \\
2 & 3 plies damaged & 200 & 1800 \\
\hline
\end{tabular}


As no failure or increased deformation was observed at maximum load, specimen 1 was unloaded and inspected. One outer ply was deliberately damaged using a hammer and chisel on the edge at several points over a $1 \mathrm{~m}$ length in the middle of the specimen. As this damage did not induce buckling upon renewed loading, the other outer ply of the specimen was similarly damaged, with the same result.

Specimen 2 was loaded to $200 \mathrm{kN}$, the maximum the hinged connection at the top could sustain safely. After observing there was no damage after $30 \mathrm{~min}$ the specimen was unloaded slowly and all 3 plies were damaged in a similar way as was done to specimen 1 .

\section{Results}

There was no failure of the glass fin under loading. Both the undamaged and damaged specimens were capable of dealing with a load at least double the maximum load expected in service. Figure 10 shows the load/displacement behaviour of the tests on specimen 1. Figure 11 shows the load displacement behaviour of specimen 2 . The initial non-linearity of the load displacement curves in Fig. 10 and 11 is the result of movement in the steel top connection, which requires some displacement before the load is fully transferred onto the fin. On unloading the displacement returned to 0 displacement at 0 force, proving that only elastic behaviour was observed.

The damaged fins have a slightly lower stiffness compared to the undamaged fins. However as the measuring apparatus measured the total displacement, the measurements are not accurate enough to calculate the actual reduction in stiffness of the damaged glass columns.

The damage did not result in short term creep, as is shown in Fig. 12, as holding the load constant did not result in additional displacement. Considering the significant levels of damage inflicted on the specimens, as shown in Fig. 13, this result is significant as the interlayer plays a significant role in transmitting forces in damaged specimen.

It should be noted that no damage propagation was observed coming from the end of the column that had been accidentally damaged before the test. Close observation during and after the tests of this damage zone revealed no cracking or other additional damage coming out of the damaged zone at the ends. So the initial damage caused no significant local tensile stresses under compression. This in itself is logical in a compression test but does show that damaged glass under the loading conditions used can still safely carry a load.



Fig. 10: Load displacement behaviour of specimen 1 
Fred Veer et al. / International Journal of Structural Glass and Advanced Materials Research 2021, Volume 5: 29.37 DOI: 10.3844/sgamrsp.2021.29.37

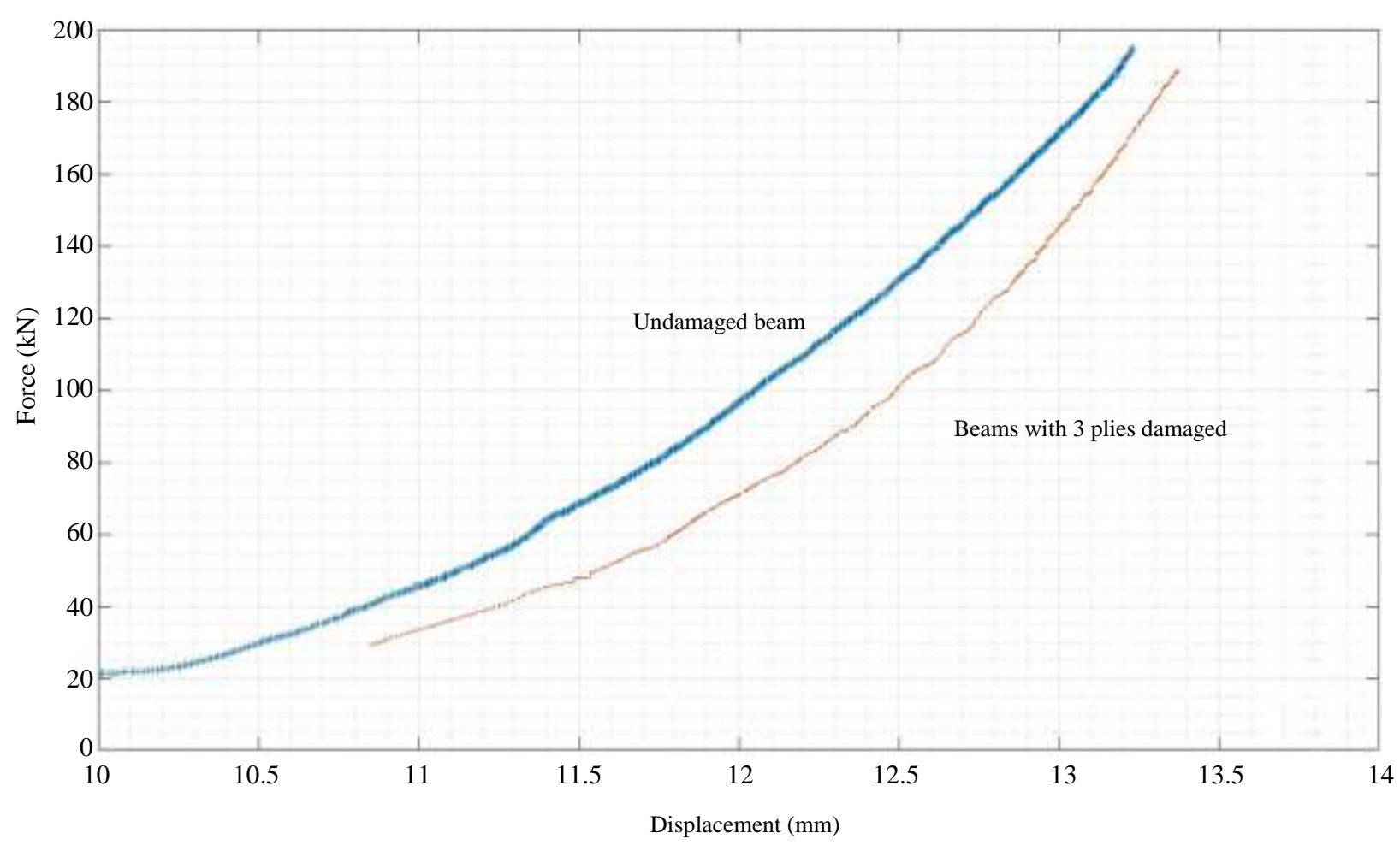

Fig. 11: Load displacement behaviour of specimen 2

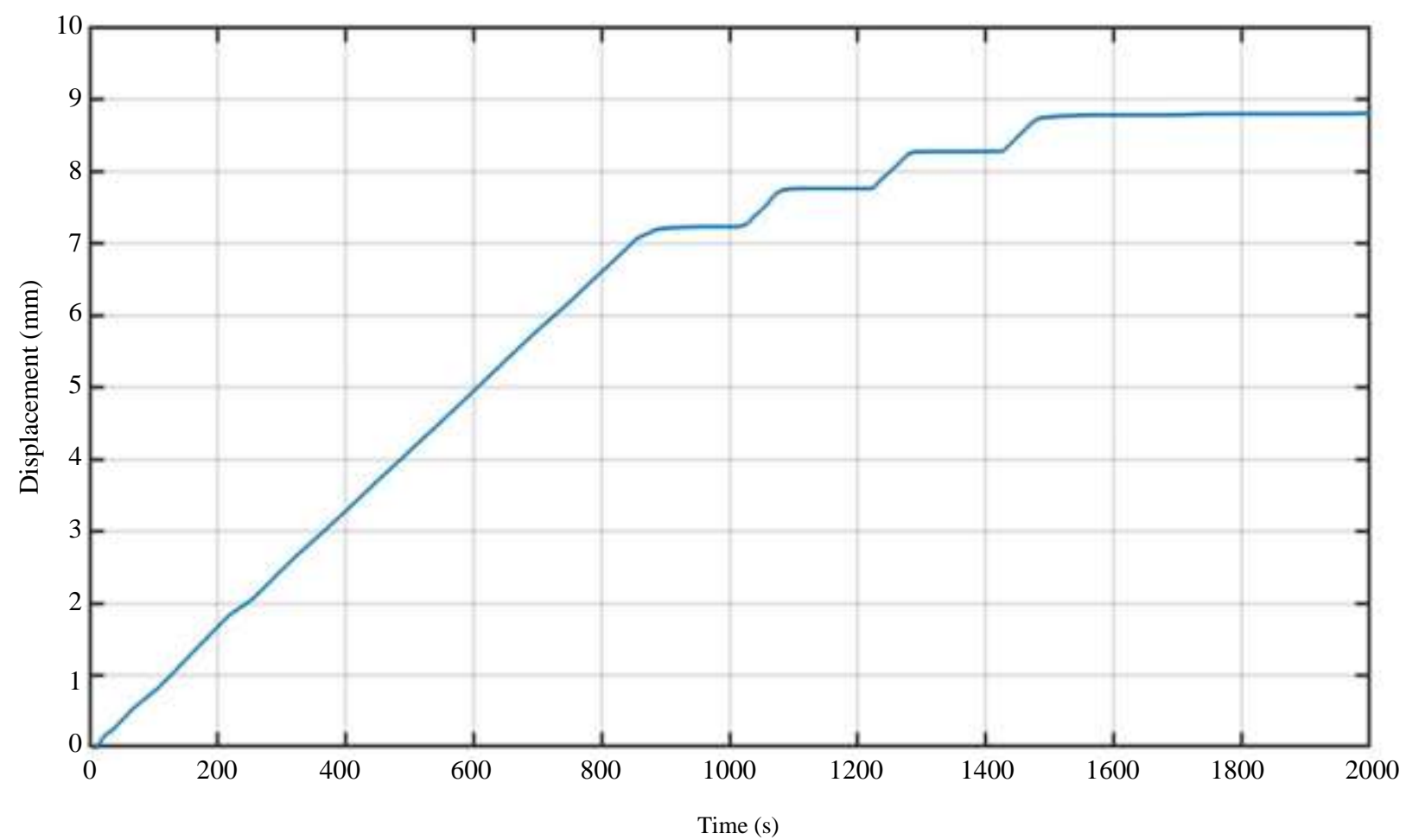

Fig. 12: Displacement time behaviour of the test on the 2 ply damaged specimen 1 




Fig. 13: Part of specimen 2 after having 3 plies damaged. Note the overlapping cracks in successive plies

Table 3: Compressive surface pre-stress measured by scalp 5 in damaged and undamaged specimens

\begin{tabular}{lll}
\hline Specimen & Zone & Compressive surface pre-stress \\
\hline 1 & Centre line undamaged & $-60 \pm 8 \mathrm{MPa}$ \\
& Centre line after damage in undamaged section at least $10 \mathrm{~mm}$ away from damage & $-58 \pm 12 \mathrm{MPa}$ \\
& Centre line in large damaged fragment at least $80 \mathrm{~mm}$ wide & $-40 \pm 15 \mathrm{MPa}$ \\
2 & Centre line undamaged & $-60 \pm 8 \mathrm{MPa}$ \\
& Centre line after damage in undamaged section at least $10 \mathrm{~mm}$ away from damage & $-58 \pm 12 \mathrm{MPa}$ \\
& Centre line in large damaged fragment at least $80 \mathrm{~mm}$ wide & $-40 \pm 15 \mathrm{MPa}$ \\
\hline
\end{tabular}

\section{Residual Stress after Damage in the Glass Fins}

Both specimen 1 and 2 were used after the tests to measure the remaining compressive surface pre-stress in the glass after inflicting deliberate damage. Measurements were taken both in the undamaged end zones and the damaged middle zone. The results of the measurements are given in Table 3. The measurements were consistent for both specimens 1 and 2 . The values given are the average result of 10 individual measurements at the center of different glass fragments. Fragments less than $80 \mathrm{~mm}$ wide could not be measured reliably with the Scalp 5 as the Scalp 5 sensor is $50 \mathrm{~mm}$ wide.

\section{Discussion}

The results show that the fin as designed is safe for use in a building such as the CCC pavilion. What was not expected is that severely damaged fins would have enough residual load bearing capacity to carry the normal design load and the redistributed load if one column is severely damaged. The results clearly show that even with severe damage to all three plies the residual load bearing capacity of an individual fin is more than twice the maximum design load for the fin. Even with the ends of the fins damaged pre-test due to accidental transport damage.

This residual strength is attributed to two factors:
- The use of heat strengthened glass which breaks into large fragments. These large fragments still maintain a level of compressive surface pre-stress after cracking of the glass and form an overlapping pattern allowing for stress transfer. In essence the cracking of the heat strengthened monolithic fin, turns it into a segmented spliced overlapping fin. As shown by (Trösch, 2015), this can be almost as efficient structurally as monolithic elements with proper lamination

- The use of Sentryglass foil as the laminating agent. The stiffer and stronger Sentryglass foil keeps the glass fragments together very well and the higher stiffness helps prevent buckling

Although similar results were observed by (Louter, 2011), for bending tests on reinforced Sentryglass laminated glass, in this case the specimens were loaded in compression and were not reinforced.

The combination of:

- Overlapping large glass fragments with some level of remaining pre-stress and an Sentryglass interlayer

- Results in a damaged specimen which is able to carry a compressive load while having enough stiffness to prevent buckling with the lateral support of the façade. This is in fact an accidental variant of the 
specifically designed segmented spliced overlapping beam system described by (Trösch, 2015)

A further important point is that the professional computer model used by structural design bureau ABT, (de Krom et al., 2000), predicted a buckling load of more than $181 \mathrm{kN}$ for an undamaged specimen. The experimental results show that a severely damaged specimen could safely carry $200 \mathrm{kN}$, which is a bigger load, without failure. This result suggests that current computer modelling for this type of structure in structural design practice underestimates the actual design strength.

\section{Conclusion}

From the results the authors conclude heat strengthened float glass laminated with Sentryglass foil used in a fin which is structurally integrated into a facade has both:

- $\quad$ Significant damage tolerance in that small damages do not significantly weaken the specimen

- Significant residual strength in that heavily damaged specimens can still carry significant loads, in this case well exceeding the maximum loads expected in service

- The heavily damaged heat strengthened Sentry glass fin should be considered as segmented spliced fin

This result should be considered to have wider implications for structural glass design and also validates the safety assumptions on which the connection details for the Delft Co-Creation Center are based.

With existing material scientific information and commercial computer programs engineers are not able to reliably calculate the critical buckling loads for these types of large laterally supported glass fins. Calculations by a professional structural engineer in this case resulted in a clear underestimate of the actual buckling strength. Although the calculated design value is conservative and thus safe, it is not conducive to the efficient use of glass as a building material.

\section{Acknowledgment}

The authors acknowledge the support of the staff, especially of Kevin Mouthaan, of the Stevin 2 laboratory of the faculty of civil engineering and geo-sciences of Delft University of Technology in doing the experiments.

The authors also acknowledge the help of the staff of $\mathrm{Si}-\mathrm{X}$ in preparing for and helping with the experiments.

\section{Author's Contributions}

Fred Veer: Organization, supervision of experiments, measuring glass data, analysis, writing the paper.
Diana de Krom: Preparatino, modelling.

Rob Nijsse: Preparatino, supervision.

\section{Ethics}

This article is original and contains unpublished material. The corresponding author confirms that all of the other authors have read and approved the manuscript and no ethical issues involved.

\section{References}

Aben, H., Anton, J., Paemurru, M., \& Õis, M. (2013). A new method for tempering stress measurement in glass panels. Estonian Journal of Engineering, 19(4).

de Krom, D., Veer, F. A., Riemens, K., \& Hoogendoorn, W. (2000). Facade become structure. Proceeding Challenging glass 7 Conference, Gent. https://journals.open.tudelft.nl/cgc/article/view/4545

Glassstress.com. (2021). Scalp 5: Portable Scattered Light Polariscope. http://www.glasstress.com/web/scalp-05/

Kasper, A. (2019). Spontaneous cracking of thermally toughened safety glass part three: statistic evaluation of field breakage records and consequences for residual breakage probability. Glass Structures \& Engineering, 4(3), 345-376.

Louter, P. C. (2011). Fragile yet ductile: structural aspects of reinforced glass beams.

Momeni, M., \& Bedon, C. (2020). Uncertainty Assessment for the Buckling Analysis of Glass Columns with Random Parameters.

Nijsse, R. (2003). Glass in structures. Birkhauser Verlag Basel

$(\mathrm{CH})$. https://searchworks.stanford.edu/view/5543860

Postel, D. J., \& Jodidio, P. (2008). Dirk Jan Postel: Transparencies. Images Publishing.

Silvestru, V., \& Englhardt, O. (2012). Numerical and Experimental Analysis of Suspended Glass Fins. advanced building skins 14| 15 June 2012.

Trösch, E. (2015). Tragverhalten von überlappend laminierten Verbundglasträgern für grosse Spannweiten (Doctoral dissertation, ETH Zurich).

USGNN. (2015). “Glass Lantern” Store the Latest Apple Patent to see the Lite. US Glass News Network. https://www.usglassmag.com/2015/04/glass-lanternstore-the-latest-apple-patent-to-see-the-lite/

van de Rotten, P., Akilo, M. A., \& van der Sluis, W. (2020, September). Redundancy tests on glass fins. In Challenging Glass Conference Proceedings (Vol. 7).

Veer, F. A., \& Rodichev, Y. M. (2016). Improving the engineering strength of heat strengthened glass. Heron, 61(2), 121-138. 